\title{
"Impact of Yoga on the Reduction of Menopausal Symptoms among Unmarried Women in Religious Societies"
}

\author{
Ms. Reena George \\ Associate professor (OBG Nursing) St.Luke's Hospital,College of Nursing Shrirampur,Maharashtra
}

\begin{abstract}
:
Back ground: Menopause is a natural process that happens to every woman as she grows older. Menopause is the end of menstruation i.e. it is a stage when women's stop having her monthly period. The average age for menopause is 52. But menopause commonly happens anytime between the ages of 42 and 56.Every women experiences certain symptoms during menopause. The more beautifully a woman tackles the symptoms the more happy life can be. ${ }^{5}$

Aim: The present study aim is to assess the impact of Yoga on reduction of menopausal symptoms. Methodology: Rating scale( $r=0.82)$ was used to assess the menopausal symptoms, the sample consist of 30 unmarried women, pre experimental one group pre test post test design was adopted.

Results: The mean post intervention menopausal symptom experience score of (77.27) was lesser than the pre intervention menopausal symptom experience score (127.37) which showed that yoga was effective in the reduction of menopausal symptoms among unmarried women. The domain wise mean difference of post test and pre test menopausal symptom experience score of unmarried women reveals that there was a significant difference in all the three domains but maximum was in "physiological factors" (30.89\%) and the least was for "psychological factors" (20.79\%). After the introduction of yoga $80 \%$ of the subjects were under mild and $20 \%$ were under moderate category and there was no association between pre menopausal symptom score and selected demographic variables.

Conclusion:Yoga is a non-pharmacological, cost effective, simple and easy to practice intervention without any adverse effects.
\end{abstract}

Keywords: Impact, Menopausal symptoms, Unmarried women, yoga.

\section{Introduction}

Midlife is a period of transition for both men and women. It brings about changes in women and it has implication on women's health. The experience of menopause is different for every woman. Menopause may be viewed as a transition of women from middle age to old age. In women this period is commonly referred as "change of life" because of the physical changes that occur in addition to the loss of child bearing capacity. Menopause is a unique stage of female reproductive life cycle, a transition from reproductive to non reproductive stage. Around $25.1 \%$ of Indian population belong to middle age out of that $12.89 \%$ belong to menopausal group. ${ }^{1}$

"Menopause is an event in life, not a disease." It is a single event in a women's life - her last menstrual period. Menarche heralds the onset of reproductive function, and menopause signals its end. ${ }^{2}$ Menopause is an event with variety of symptoms, As cited in "A Guide to problem associated with menopause" various menopausal symptoms experienced by the women are irritability, lethargy, depression flushes, night sweats, headaches, forgetfulness, weight gain, insomnia, joint and muscle pain, palpitations, crying spells, constipation, dysuria and decreased libido. ${ }^{3}$

The number of women approaching menopause is increased nowadays and majority of women may spend greater part of their life in postmenopausal years. About $75 \%$ of women at menopause undergo various changes physically, psychologically and $25 \%$ needs medical advice and only $5-10 \%$ of women need reassurance. ${ }^{4}$ Yoga, an ancient science, can help women cope up with menopause and help to develop a state of their body and mind. Yoga posters, meditation, relaxation which can improve concentration, increase oxygen levels in the blood and assist the body in healing itself. ${ }^{5}$ Relaxing asana or relaxation techniques helps to develop inner awareness and unfold the higher level of consciousness. Relaxation, slow breathing and calming the mind, form the triplet of yoga featured in Patanjali yoga. It is here that energy channelization and conservation processes are harnessed and the overshoots and imbalance of the bodily functions are controlled. ${ }^{6}$ Yoga offers more than a way of life, "For yoga, cumbersome or difficult breathing exercises are not necessary. What is essential is that the consciousness of the individual must be lifted up. ${ }^{7}$ 
Today, an unprecedented number of women are either approaching or in the midst of menopause, and are seeking information and tools to help them manage their physical, emotional and spiritual changes. "Yoga" and the "wisdom of menopause" will show you and you can experience your passage into menopause as a positive event." 8

The present study offers a unique contribution to the understanding of effect of yoga for the reduction of menopausal symptoms in women.

\section{Objectives}

2.1 To identify the menopausal symptoms among unmarried women before and after administering yoga by using rating scale.

2.2 To evaluate the effectiveness of yoga on the reduction of menopausal symptoms among unmarried women.

2.3 To determine the association between the menopausal symptoms with selected variables.

\section{Research Methodology}

3.1Research approach: Evaluative approach

3.2Research design: Pre experimental, one group pre test-post test design

3.3Setting: Christian religious convents at Mangalore

3.4Participants: Menopausal Unmarried women

3.5Samping technique: Purposive sampling technique

3.6Sample: 30 unmarried women

3.7Dependent variable: Menopausal symptoms

3.8Independent variable:Yoga

3.9Tool used: Rating scale to assess the menopausal symptoms

4.0Data analysis: Descriptive and Inferential statistics

\section{Results}

Table4.1: Frequency and Percentage Distribution of Unmarried Women with Menopausal Symptoms according to their Baseline Characteristics.

The data presented in Table4. 1 shows that in group highest number of subjects were found in the age group of $46-50$ years $(36.7 \%)$ and least $(13.37 \%)$ were found in the age group of $\leq$ 45years. educational status of the subjects reveals that $50 \%$ were graduates and $6.7 \%$ were professionals. Majority of the subjects $(60 \%)$ were teachers, health professionals and retired were equal in number $(3.3 \%)$. Alternative Therapies attended shows that $(60 \%)$ of subjects attended therapies like meditation and $(26.7 \%)$ were found to be non attendees of any therapies. Majority of the subjects $(53.3 \%)$ had irregular menstrual cycle, (30\%) had attained menopause and $16.7 \%$ have regular menstrual cycle. $\mathbf{N}=\mathbf{3 0}$

\begin{tabular}{|l|l|l|l|}
\hline Sl. No & Variables & Frequency (f) & Percentage (\%) \\
\hline $\mathbf{1}$ & Age in years & & \\
& $\leq 45$ & 4 & 13.3 \\
& $46-50$ & 11 & 36.7 \\
$\mathbf{2}$ & $51-55$ & 9 & 30.0 \\
& $\geq 55$ & & 20.0 \\
& & - & \\
& Education & 3 & - \\
& S. S. L. C & 15 & 10.0 \\
& Higher Secondary & 4 & 50.0 \\
& Graduate & 2 & 33.3 \\
$\mathbf{3}$ & Post Graduate & & 6.7 \\
& Professional & 18 & \\
& & 7 & 60.0 \\
& Occupation & 3 & 23.3 \\
& Teacher & 1 & 10.0 \\
& Social worker & 1 & 3.3 \\
$\mathbf{4}$ & Clerical work & & 3.3 \\
& Health Professional & Retired & 10 \\
& & - & 60.0 \\
& Alternative therapies & 4 & - \\
& Meditation & - & 13.3 \\
\hline
\end{tabular}




\begin{tabular}{|l|l|l|l|}
\hline $\mathbf{5}$ & Yoga & 8 & 26.7 \\
Exercise & Any other (Specify) & & \\
Nil & 5 & 16.7 \\
& Menstrual Cycle & 9 & 53.3 \\
& Regular & 30.0 \\
& Irregular & & \\
3. Ceased & & \\
\hline
\end{tabular}

Table4.2: Mean, Standard deviation, median and $\%$ mean score of pre test and post test menopausal symptom score.

Data in table4. 2 shows that mean post test score (77.27) is lower than the pre test menopausal symptom score (127.37). The \% mean of post test menopausal symptom score (38.635) is less than the \% mean of pre test menopausal symptom score (63.68). $\mathbf{N = 3 0}$

\begin{tabular}{|l|l|l|l|l|l|l|}
\hline Variable & Mean & SD & \multicolumn{2}{l|}{ \% mean score } \\
\cline { 2 - 7 } & Pre & Post & Pre & Post & Pre & Post \\
\hline Menopausal symptom & 127.37 & 77.27 & 20.363 & 12.071 & 63.68 & 38.635 \\
\hline
\end{tabular}

Maximum score : 200

Table4.3 : Area wise Mean, SD, Median and \% mean of the pretest and post test menopausal symptoms score.

Data in the table 4.3 and figure (1) shows that the \% mean menopause symptom score of pretest was maximum for physiological factors $(66.89 \%)$ and minimum was found in social factors $(59.95 \%)$, whereas the \% mean menopausal symptom score of post test was maximum in the area of psychological factors $(43.51 \%)$ and minimum in the area of social factors $(35.31 \%)$. The present data also shows that the maximum \% mean reduction of menopausal symptom score has occurred in the area of physiological factors $(30.89 \%)$ and least reduction has occured in the area of psychological factors $(20.19 \%)$. $\mathbf{N}=\mathbf{3 0}$

\begin{tabular}{|l|l|l|l|l|l|l|}
\hline \multirow{2}{*}{ Areas } & \multicolumn{2}{|l|}{ Mean } & \multicolumn{2}{l|}{ SD } & \multicolumn{2}{l|}{ \% Mean score } \\
\cline { 2 - 7 } & Pre test & Post test & Pre test & Post test & Pre test & Post test \\
\hline Physiological & 40.13 & 21.60 & 8.677 & 4.621 & 66.89 & 36.00 \\
Psychological & 48.87 & 33.07 & 7.195 & 4.487 & 64.30 & 43.51 \\
Social & 36.37 & 22.60 & 6.349 & 4.636 & 59.95 & 35.31 \\
\hline
\end{tabular}

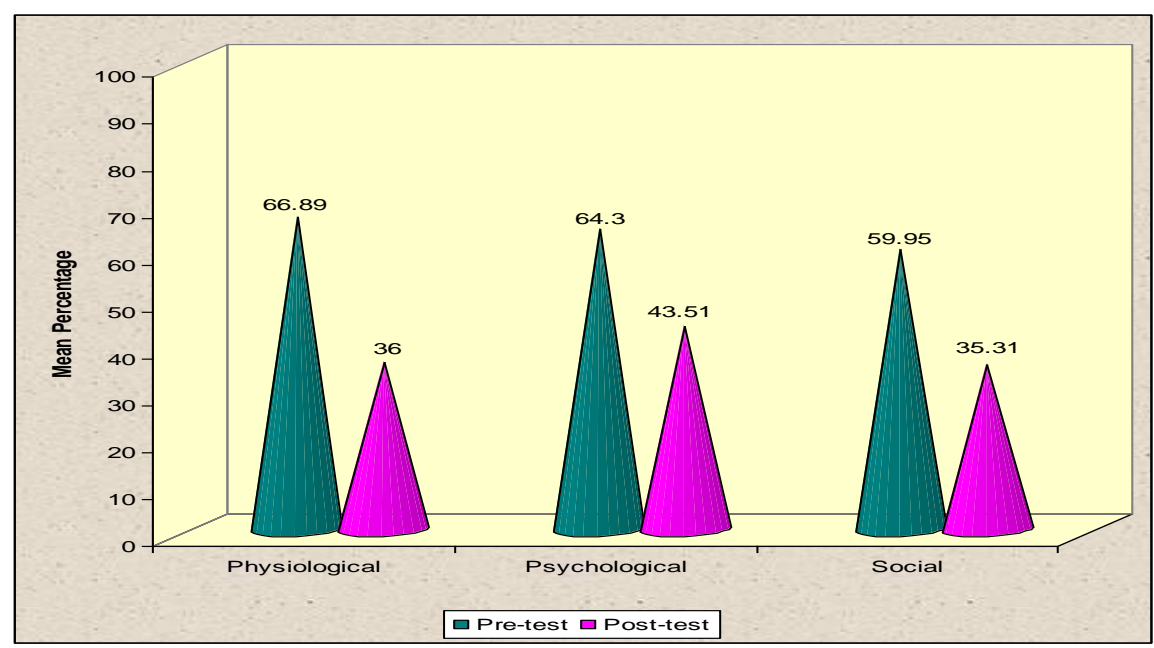

Table 4.4: Distribution of subjects according to the grading of pre test and post test menopausal symptom score.

Data from table 4.4 shows that in the pretest menopausal symptom score most of the subjects (63.3\%) had moderate menopausal symptoms and $36.7 \%$ had severe menopausal symptoms. After the yoga none of them experienced severe menopausal symptom, but most of them (80\%) were under the mild category. $\mathbf{N}=\mathbf{3 0}$ 
Maximum score 200

\begin{tabular}{|c|c|c|c|c|c|}
\hline \multirow{2}{*}{$\begin{array}{l}\text { Range of } \\
\text { Percentage }\end{array}$} & \multirow[t]{2}{*}{ Category } & \multicolumn{2}{|c|}{ Pre test } & \multicolumn{2}{|c|}{ Post test } \\
\hline & & $\mathbf{F}$ & $\%$ & $\mathbf{f}$ & $\%$ \\
\hline$<40$ & Mild & .00 & .00 & 24 & 80.0 \\
\hline $41-70$ & Moderate & 19 & 63.3 & 6 & 20.0 \\
\hline$>71$ & Severe & 11 & 36.7 & .00 & .00 \\
\hline
\end{tabular}

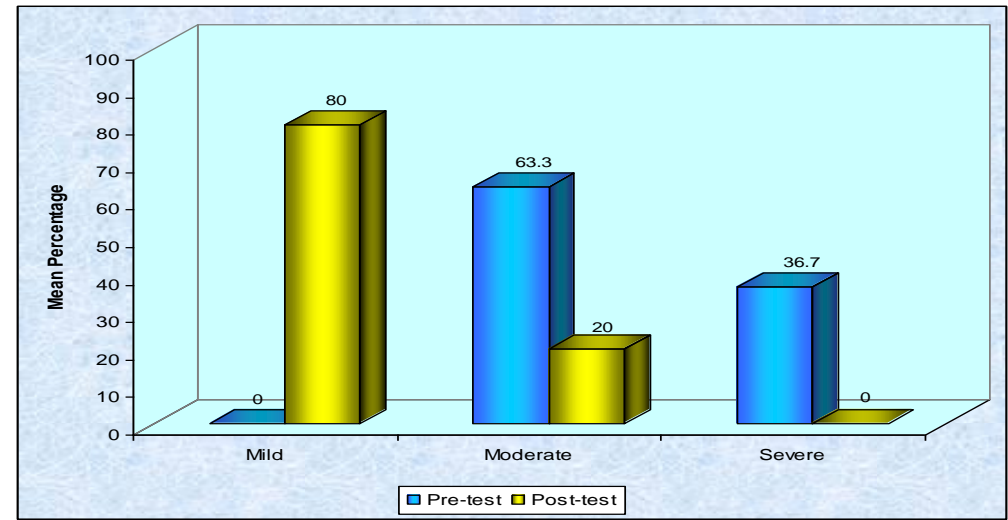

Table 4.5: Chi-square test showing the association between pre-test menopausal symptom and selected variables. $\mathrm{N}=30$

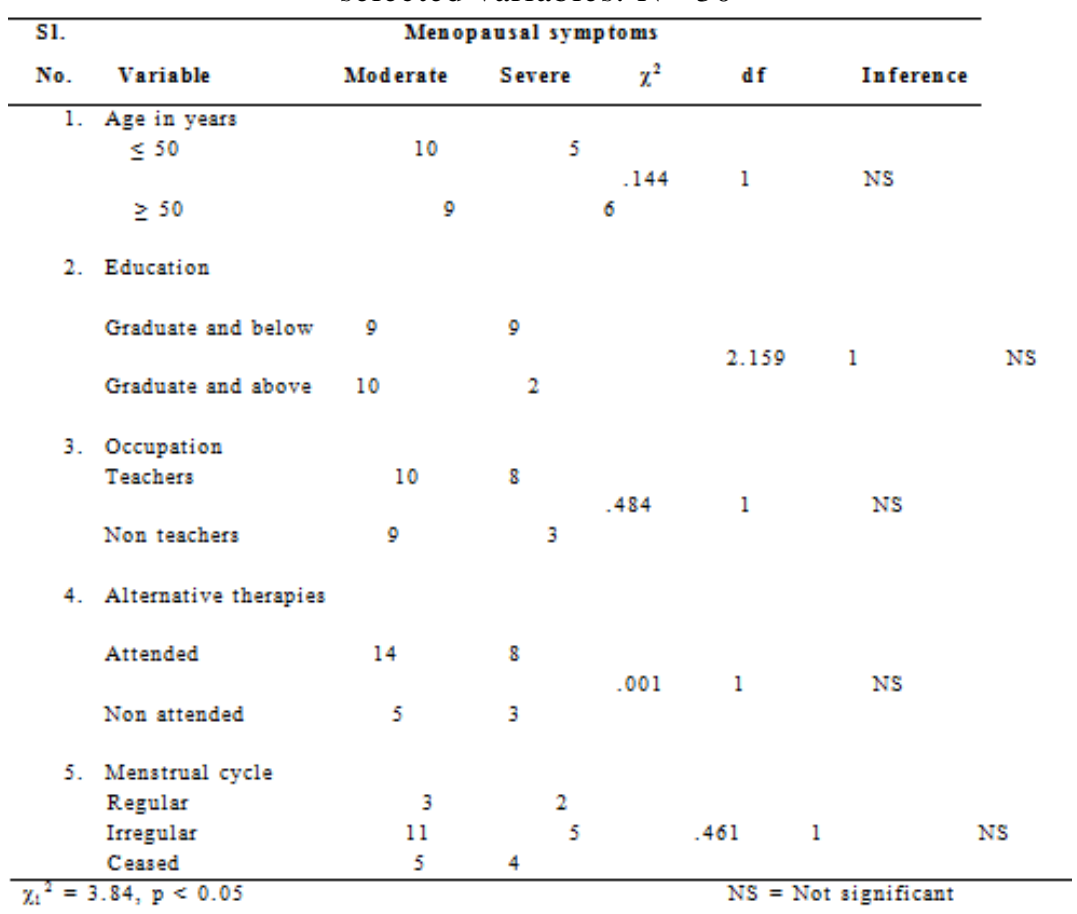

The data presented in the table 4.5 reveals that there is no significant association between the pre-test menopausal symptom experience and selected variables since the calculated values are lower than the tabled value $\left(\chi^{2}=3.84\right)$. Therefore the null hypothesis was accepted and research hypothesis was rejected.

Table 4.6: Opinionnaire regarding yoga. N=30 I Feel Yoga

\begin{tabular}{|c|c|c|c|c|c|c|}
\hline Statement & & igly ag & & Agree & & certain \\
\hline & & $\%$ & & f $\%$ & & $\%$ \\
\hline Helps in relaxation. & 24 & 80 & 6 & 20 & & \\
\hline Helps to sleep better. & 23 & 76.6 & 7 & 23.3 & & \\
\hline Increases the concentration. & 24 & 80 & 6 & 20 & & \\
\hline Strengthens the abilities. & 16 & 53.33 & 12 & 40 & 2 & 6.6 \\
\hline Reduces anxiety. & 23 & 76.6 & 7 & 23.33 & & \\
\hline Reduces menopausal & & & & & & \\
\hline Symptom. & 30 & 100 & & & & \\
\hline
\end{tabular}


Data in the table 4.6 depicts that $80 \%$ of the subjects strongly agreed and $20 \%$ agreed that the yoga helps in relaxation and increases concentration. The subjects' also strongly agreed $(76.66 \%)$ and $23.3 \%$ agreed that yoga helps to sleeps well and reduces the anxiety. Whereas $53 \%$ of the subjects strongly agreed and $40 \%$ of them agreed and $6.6 \%$ were uncertain about whether yoga strengthens the abilities. But $100 \%$ of them strongly agreed that yoga reduces the associated symptoms.

\section{Conclusion}

The results revealed that, there is significant reduction on menopausal symptom after yoga therapy that is after the yoga therapy none of the subjects experienced severe menopausal symptoms but most of them $(80 \%)$ were under the mild category. The findings of the study are helpful to implement the alternative therapies to improve the client education on self care practices. Many studies have proved that yoga can improve the quality of life and it is proved to be an effective remedy for many conditions like menopause, hypertension, diabetes, cancer, dysmenorrheal etc. Yoga will help to reduce anxiety and stress of today's modern life. It also helps to improve strength, flexibility, co-ordination and range of motion. Yoga when practiced regularly can balance the body chemistry. This would provide physical, psychological and spiritual benefit.

\section{Limitations of the study:}

$\checkmark$ Since the study was limited to only two religious societies at Mangalore, which imposes limits on generalization.

$\checkmark$ The study was carried out on a small sample which also imposed limits on generalization.

$\checkmark$ The study was limited to unmarried women living in religious societies.

$\checkmark$ Yoga practice could have been given for longer duration which would have produced more significant results.

\section{References}

[1]. ICMR (2003), retrieved from www.icmr.in/annual/nirrh/2003-2004/ executive sum.pdf

[2]. A guide to problem associated with menopause retrieved from http://www.indiaparenting.com/health.

[3]. Barbo. M. Dorothy, Physiology of menopause, Medical clinics of North America, 1987, 71:11-19.

[4]. World health report, 'symptoms of menopause and their treatment, Geneva, 1990.

[5]. Yogahealthywomen.org. http://healthywomen.org/content.cfm $\mathrm{L}_{1-3}$ and $\mathrm{L}_{2-94}, 2004$, April 11

[6]. Nagaarthna R, Nagendra HR, Integrated approach of yoga therapy for positive health. $2^{\text {nd }}$ ed, Bangalore swami Vivekannanda, yoga prakashaana; 2004.

[7]. Yoga: More than a way of life, The Indian express-wellness. 18/7/2008.

[8]. Suza francina, the yoga of menopause; Alternatives to hormone: http//www.entalone.com/article/4165 html. 